\title{
CONTINUIDADE, MUDANÇA E TEMPO. O problema da periodização e outros problemas no estudo da História.
}

\author{
CELIA FREIRE A. FONSECA \\ Assistente da Cadeira de História do Brasil, na Faculdade \\ de Filosofia da Universidade Federal de Pernambuco.
}

Ao considerarmos a História encontramos, sempre, dois complexos que estão presentes como uma sombra, fora e ao mesmo tempo resultante da combinação dos inúmeros elementos atuantes: a continuidade e a mudança. Provenientes, ambos, de fatôres internos e externos, necessidades, tradições, interêsses, objetivos, necessários às bases temporais, materiais e espirituais das comunidades e civilizações.

A continuidade e a mudança parece-nos resultantes daquele equilíbrio dinâmico dos vários elementos, sempre em movimento, a desfazer-se e a se refazer em novas bases, tal como para êle chamou a atenção o conceito darwiniano na História Natural. Daí em diante o evolucionismo não mais foi ignorado pelas outras ciências, não importam as restrições e oposições levantadas. Era uma afirmação vigorosa da influência do tempo na Ciência Natural, como antes enunciaram alguns precursores e como mais tarde a corrente historicista desenvolveria e insistiria. A História, na qual é o Tempo fator ontogênico e ubíquio, não poderia deixar de ser mais fortemente impregnada dêsse sentido evolucionista, apesar de retificações e adaptações ao conceito darwinista pròpriamente. De fato, o tempo histórico é, sempre, contínuo e, também, mudança. Daí, mesmo, a grande dificuldade e os problemas que surgem quando do estudo de épocas e civilizações. A percepção de épocas, aliás, já traz consigo um conceito discriminativo que é o de periodização. Periodização que envolve vários problemas e leva o estudioso a se defrontar com uma série de dificuldades.

Não seria necessário periodizar se pudéssemos abranger tôda a evolução humana sem estabelecer marcos nem características. Mas; condicionados às épocas e sob a influência dos espaços, próximos e 
distantes, não podemos compreender melhor os acontecimentos se os não relacionamos ao período que os envolve.

Apesar de, em grande parte, serem os períodos artificiais, não podem ser ignorados na História devido, justamente, à influência dos dois fatôres ressaltados de início, isto é, a continuidade e a mudança.

Com as transformações de técnicas, produção, estilos de vida, mentalidade e ideais de comunidades nacionais ou mesmo universal, os períodos como que surgem por si mesmos. Forçoso é tomar conhecimento das mudanças que se impuseram e estabeleceram estilos de vida característicos que constituem como uma marca de determinados períodos ou subperíodos históricos. Assim, ninguém confundiria um homem do Renascimento com um outro do Medievo, ainda mesmo quando viveram, ambos, no mesmo continente, como a Europa dos séculos XIII, XIV ou XV. Na Europa dêsses mesmos séculos, mas em regiões diversas são diferentes os indivíduos que viveram períodos técnicos, sociais, políticos e mentais de épocas diferentes como, por exemplo, um veneziano e um franco. Realmente é enorme a diferença de um veneziano ou um florentino do século XV, comerciante e relacionado com o mundo e um rude franco, telúrico e ainda ligado às concepções e estilo de vida da época feudal. Fatos como êste, comuns na História, traz nova ordem de problemas, ligados à dificuldade de sincronização entre as culturas e civilizações, bem como ao conceito de áreas culturais, dada as íntimas ligações da História com a Geografia. Esse conceito, tão bem explorado nos estudos de Antropologia Cultural, tem grande importância no problema de periodização na História. O problema de periodização não é, pròpriamente, distinguir uma época da outra quando as diferenças estão bem caracterizadas e os estilos de vida aparecem como quase opostos. Desde que estas diferenças existem e se evidenciam em períodos dessemelhantes não é difícil distinguí-los e aceitá-los como tais a dificuldade é assinalar quando se iniciam ou quando terminam. Início e fim, aliás, relativos, pois, como bem assinala Marcel Reinhardt (1), não há um corte, mas uma passagem. Realmente, surpreendenos quando em contacto com os períodos finais de uma época, impérios ou éras, certos traços já visíveis e até mais ou menos regularmente desenvolvidos e em expansão do período seguinte, que tomará seu lugar. As tendências, mais fàcilmente observadas na perspectiva histórica porque se afirmaram e se expandiram, estão, apesar disso, já delineadas e visíveis nos séculos do período anterior, em geral. Também as condições responsáveis pelas novas direções, na constân-

(1). - Marcel Relnhardt, L'enseignement de l'Histoire et ses problèmes, Presses Universitatres de France, Paris, 1957, p. 16. 
cia de sua presença no período que termina, fornece-nos os elementos de compreensão ou explicação das transformações em marcha. $\mathrm{Na}$ mistura de outros traços, choques e vitórias momentâneas de outras correntes, além do poder de resistência e reação da tradição mesmo quando enfraquecida, mais difícil é, muitas vêzes, ao contemporâneo dos acontecimentos que ao póstero perceber com nitidez a tendência dominante de sua época. Mesmo porque os interêsses e desejos de cada um, ainda mesmo quando imprecisamente desinteressados, aquêle "nariz de Cleópatra" de que fala Gilberto Freyre em sua Sociologia (2), impulsionaria o participante a se apegar aos traços que mais lhe conviria ou corresponderia aos seus desejos pessoais ou de grupo.

Com a passagem dos séculos o historiador vê o desenrolar mais ou menos total dos fatos, além de uma visão de conjunto dificilmente possível a quem está dentro da área dos acontecimentos, em geral mais limitada do que êle próprio imagina. Assim, os estilos de vida e contornos próximos parecerão ou esconderão todo o resto, como já foi assinalado por mais de um estudioso. Marc Bloch toma como exemplo um general que deva escrever o relatório da batalha em que tomara parte mas, mesmo assim, tem necessidade de utilizar os informes de seus tenentes e ajudantes de campo, além de suas próprias experiências e observações (3). A objeção será que, pelo menos, os contemporâneos são testemunhas de sua época. E êsses testemunhos, quando conjunto de várias procedências e autorias devidamente criticadas, são muito utilizados e apreciados pelos historiadores. Mas não nos esqueçamos que, mais importante e trazendo indicações mais precisas e profundas sôbre os fatos são as chamadas fontes históricas; isto é, desde os monumentos e restos materiais das culturas e civilizações até os textos de lei, códigos, decretos e medidas efetivas sôbre as questões e a época estudada. Aliás, os testemunhos mais interessantes como documentação de um período, em geral, são os registros sem comentários da vida diária, decretos e acontecimentos, quando não foram feitos de encomenda. Daí o valor do registro burocrático, sem interpretações, como os arquivos de uma chancelaria ou de um ministério. Apenas é preciso saber procurá-los e aproveitá-los. O fato é que, exceção das fontes históricas pròpriamente, se utilizamos testemunhos escritos de menor rigor que os códigos e decretos, inclusive as também muito importantes leis menores aplicadas ou adaptadas, nada dá melhor a

(2). - Gilberto Freyre, Sociologia, Vol. I, Introdução, Livrarla José Olympio Editôra, Rio, 1945, pp. 27, 30 e 37.

(3). - Marc Bloch, Introducción a la Historia, Ed. Fondo de Cultura, Mexico, 1952, pp. $42-43$. 
significação de uma época, dos objetivos ou da dominação de uma classe, de ưm povo sôbre outro, do sentido e direção de uma cultura ou civilização, do que êstes frios registros e providências. Inclusive nas suas adaptações e mesmo deformações face a uma realidade mais forte, o que mostrará certa dicotomia entre o centro legislador e a região que reage, ao mesmo tempo que certas diferenças de objetivos ou condições.

Traços menos espalhafatosos, o dêsses registros em geral enfadonhos, menos aparentes que o reboliço de atitudes mais barulhentas ou populares porém mais superficiais e enganosas. Justamente o barulho ao redor de aparências torna mais difícil aos contemporâneos a percepção das correntes mais efetivas e, assim, são testemunhas mais frequientes das superficialidades de sua época do que dos movimentos mais profundos. $\mathrm{E}$ há, ainda, os elementos subjetivos a considerar. Se entra elementos subjetivos em quantidade na apreciação e posição dos estudiosos dos fatos sociais distanciados no tempo por séculos, imagine-se a repercussão dêsses fatos nos contemporâneos, sem falar na ignorância dos movimentos de bastidores ou correntes menos visíveis e menos próximas. A experiência de cada um, aliás, torna claro o quanto de paixão e subjetivo há no testemunho dos contemporâneos, sem falar nas falhas de percepção. $O$ caso de muitos testemunhos ilustres, de cultura superior à média dos seus contemporâneos, é elucidativo, tanto em épocas revolucionárias como em épocas menos barulhentas, de mudanças consideráveis porém menos espetaculares que as lutas armadas, com seus choques e atritos gritantes. Apesar disso, certos acontecimentos, pelas inovações radicais, originalidade inesperada ou características muito diversas da tradição anterior fornece aos contemporâneos uma idéia de sua importância ou fôrça revolucionária, tal como se viu com a descoberta da América, a chamada revolução industrial, reforma religiosa, revolução francesa ou, nos tempos mais antigos, o advento do Cristianismo. De modo geral, as consequiências de mudanças tão amplas e de raio de ação tão extenso são percebidas mais por intuição e, muitas vêzes, traz mais um sentimento de insegurança e mau augúrio que de compreensão do sentido mais largo dos horizontes que abre. Mesmo porque, no primeiro momento, não podem substituir de imediato os alicerces que destruiu ou deslocou, mesmo quando apodrecidos e já sem conteúdo efetivo. Apesar dessa mudança brusca e extensa - e só por isso pode ser percebida por certa parte dos contemporâneos - há sempre uma continuidade na sucessão, mesmo quando menos aparente. Por isso Fernand Braudel diz ser a História 
"uma dialética da duração" (4),

acentuando e ligando a essa condição

"o estudo do social, de todo o social e portanto do passado $e$ também do presente, inseparáveis um do outro" (grifo nosso).

E', também, a idéia de Marc Bloch quando diz, sôbre o contínuo e a mudança no tempo, que

"da antítese dêsses dois atributos provem os grandes problemas da investigação histórica" (5).

Considere-se, além disso, o fato da evolução nem sempre se dar ao mesmo tempo nos vários setores de uma sociedade ou civilização, apesar das grandes mudanças afetarem, cêdo ou tarde, os demais aspectos. Há setores mais resistentes às mudanças e ali as tradições resistem melhor, talvez porque menos ligados aos interêsses imediatos ou urgentes da sociedade em questão. Por outro lado, se o curso histórico é uno, devido à riqueza de componentes e ao complexo responsável pelas combinações constantes e inesperadas, podemos registrar períodos característicos que os particulariza e distingue uns dos outros. Individualização de períodos que torna difíril o estudo científico das ciências culturais, de características tão diferentes das ciências naturais. Estas últimas, caracterizadas por Xénopol como ciências dos fatos de repetição e por isso com a possibilidade de leis que fogem às ciências em que, jamais, os fenômenos podem se repetir da mesma maneira e serem reconstituídas as mesmas condições em que se verificaram. E' a complexidade e o número elevado e imprevisível de combinações e elementos que torna impossível uma repetição ou reconstituição autêntica de fatos históricos com suas consequiências em cadeia e, portanto, previsões válidas. Pois jamais seria a História o estudo superficial de acontecimentos, nomes e datas, ornamental e quase fútil, mas a investigação de suas causas e dos fenômenos de relação, o estabelecimento de fio ou nexo de causalidade que nos permita compreender suas direções, mudanças e razões em cada momento característico. $\mathrm{E}$, mesmo, compreender a tendência predominante através dos séculos, com seus avanços e recuos, o porquê da aceleração das mudanças ou predominância da continuidade em certos momentos daí porque, hoje, a psicologia, inclusive psicologia coletiva, é de tanto interêsse para a História. Sem falar na economia, sociologia,

(4). - Fernand Braudel, Historia e Sociologia, do livro Tratté de Soclologie publicado sob a direção de Georges Gurvitch, cap. IV, Par1s, 1958, e traduzido para o Boletím de História, Ano III no 6, Faculdade Nacional do Filosofia, Rio, 1961, p. 67.

(5). - Marc Bloch, ob. cit., p. 27. 
etnologia e outras, devido ao aprofundamento de aspectos básicos de suma importância para a compreensão dos movimentos históricos. Em todos êsses aspectos o Tempo é fator primordial, o historiador sente isso profundamente, independente quase de sua formação, como por intuição. E, embora tenha sido grande a valorização dada pela corrente historicista à posição do tempo em tôdas as ciências, sobretudo no plano maior do conjunto, nos aspectos de evolução e mutações que podem dar uma dimensão nova e mais profunda às investigações e descobertas, é no estudo da História, isto é, da sociedade no tempo, que esta dimensão guarda tôda sua fôrça e potencialidade, como é natural. Porque o tempo é o clima mesmo da História. Para nós, seria mesmo a História a relação da sociedade com o tempo, condição do seu desenvolver-se, um oferecendo a outra o campo onde tem lugar a sua evolução, o ambiente indispensável para o crescer e combinar-se de elementos e fôrças só possível ao contacto dêsse elemento mais amplo e imponderável que é o Tempo - e seria isso que a distinguiria da Sociologia, apesar de seus inúmeros pontos comuns. Como escreveu Marc Bloch ao classificar a História como "Ciência dos homens no tempo", o historiador não pensa só no humano mas, também, no tempo, pois

"La atmosfera en que su pensamiento respira naturalmente es la categoria de la duración" (6). Diz, ainda: "al tiempo de la historia, realidade concreta y viva abandonada a su impulso irrevertible, es el plasma mismo en que se bañan los fenómenos y algo así como el lugar de su inteligibilidad".

A reflexão citada lembra-nos a preocupação que nos parece constante em Henri Berr, o organizador e dirigente até 1954, ano de sua morte, da notável coleção L'évolution de l'Humanité, inclusive em inúmeros de seus lúcidos Prefácios às obras daquela coleção quando, ao tratar de grandes movimentos da História mostrava quanto, mais do que o número de anos e até séculos em que se manteve uma tendência interessa sua significação na evolução cultural e humana, isto é, dentro do tempo histórico inteiro. Apesar de parecer contraditório ao primeiro momento, na verdade o tempo menor, delimitação artificial, está contido no maior ou, melhor, no tempo todo inteiro. Da mesma forma os acontecimentos, mais compreensíveis dentro dos períodos, só nos dão sua significação maior dentro de todo o conjunto, isto é, da História universal. Na verdade, o que Henri Berr assinalava, como o mais importante na História, era a busca daquele nexo de causalidade, com suas origens, afirmações, transformações e sobrevivências - na dinâmica que Hegel apreen-

(6). - Ibidem, p. 26. 
deu tão magistralmente ao exprimí-la em seu processo dialético. $\mathrm{Na}$ investigação da causalidade os fatôres continuidade e mudança dentro do tempo apresenta-se a todo o momento diante do historiador e atentar para êles é tomar conhecimento do problema da causalidade mesma, na História .

Situar o fato em seu conjunto também é preocupação de Marc Bloch quando toma como exemplos a conquista da Gália e o movimento iniciado por Lutero e, escreve, que interessa

"mucho más señalar el lugar exacto que ocupa la conquista de la Galia en la cronologia de las vicisitudes de las sociedades europeas; y sin negar en modo alguno lo que haya podido contener de eterno una crisis del alma como la del hermano Martín, no creerá haber rendido cuenta exacta de ella más que después de fijado con precisión su momento en la curva de los destinos simultáneos del hombre que fué su héroe y de la civilización que tuvo por clima" (7).

E' o conceito de explicação, bem diverso do antigo sôbre a História e que Henri Berr distingue ao dizer que, na concepção da História intuitiva os fatos recolhidos

"sous ses diverses formes, cherche, plus ou moins prudemment, à reproduire la vie" enquanto "l'histoire-science cherche a l'expliquer" (8).

E esclarece, ainda, o mesmo autor:

"étudier et préciser le rôle des divers éléments explicatifs dans l'ensemble du passé humain",

mas, alerta o historiador contra pretensões muito ambiciosas, pois considera prematuro e arriscado improvisar, já, uma

"Synthèse totale, - l'Histoire universelle, la Weltgeschichte, ... est-elle réalisable, et comment? L'est-elle dans l'état present de l'érudition?".

Daí ligar o penetrante analista a síntese histórica ao progresso geral das ciências, que êle precisava como as relações da Síntese Histórica com a síntese geral das ciências. Pensamento, como êle mesmo assinala (9), partilhado por Marc Bloch de quem transcreve a frase:

"Chaque science prise isolément ne figure jamais qu'un fragment de l'universel mouvement vers la connaissance".

(7) . - Ibidem, pp. 26-27.

(8). - Henr1 Berr, La synthèse en Histoire. Son rapport avec la synthèse général, Editions Albin Michel, Nouvelle fdition revue, Paris, 1953, pp. 253-254 e 292.

(9). - Ibidem, p. 289. 
O mesmo conceito era esposado por Lucien Febvre e por seu sucessor na cátedra do Collège de France, Fernand Braudel, atual presidente da seção de Ciências Econômicas e Sociais da Ecole Pratique des Hautes Etudes. Pensamento amplo, portanto, mas preciso, sem as ilusões de tudo querer abarcar, em geral às custas de uma falsificação ou deturpação dos acontecimentos, mesmo em suas grandes linhas. Inclusive porque as ciências culturais são recentes como ciências, só na segunda metade do século passado constituiram-se de maneira mais sistemática, com independência e métodos próprios. Os grandes representantes da historiografia francesa, lúcida e equilibrada, embora reconheçam e orientem o estudo da História ao lado das outras ciências, sobretudo culturais, não incentivam o que Braudel chamou "um imperialismo juvenil" a que se inclinou não só a História como tôdas as ciências culturais ainda em começos dêste século. Já Gilberto Freyre assinalava a mesma tendência imperialista na Sociologia (10) e, o que diz sôbre esta ciência, na penetrante e moderna Introdução que escreveu em 1945, pode-se dizer que se aplica a tôdas as ciências culturais - elas como que se aproximam em uma síntese mais ampla, como queria Henri Berr, e Braudel ainda recentemente, no artigo citado. Realmente, a tendência geral das Ciências Culturais parece confirmar essa posição lúcida que, na pluralidade de aspectos, não ignora os pontos de contacto e certa tendência à unidade (11). Na História, em meio a esta pluralidade as dias constantes, continuidade e mudança, são visíveis, ora uma ora outra mais em evidência ou sob novas formas, porque nela o Tempo está sempre presente, sensível e quase palpável.

(10). - Gilberto Freyre, obr. cit., pp. 16-17.

(11). - Ibidem, pp. 19-24. 